\title{
An Evaluation of the Fungi Isolated from Sub- epidermal Region of Post-harvested Stored Wheat Grains
}

\author{
Shiju Mathew ${ }^{1}$, George Thomas ${ }^{2}$, Tufail Ahmad ${ }^{3}$ \\ ${ }^{1}$ Ministry of Higher Education, Aksum University, Aksum (Ethiopia) ${ }^{2}$ Department of Molecular Biology \& Genetic Engineering, Allahabad \\ Agricultural Institute -Deemed University, Allahabad 211007 (India) ${ }^{3}$ Department of Agriculture Process and Food Engineering, Allahabad \\ Agricultural Institute - Deemed University, Allahabad 211007 (India)
}

\begin{abstract}
The criteria of wheat quality are as varied as their different uses. Wheat, which is suitable for a particular use / product, may have certain characters that make it entirely unsatisfactory for other purposes. The storage fungi damage the grains in several ways; they reduce the germinability, produce undesirable odor and kernel discoloration, decrease the food value and also produce toxins injurious to the health of consumers. The sub-epidermal mycoflora of stored wheat grains predominantly consisted of ubiquitous mould genera Aspergillus, Alternaria and Penicillium possibly because of their omnipresence, capacity to grow on all possible substrates and a wide range of temperature and humidity. The most frequent species observed in the stored wheat grains of Aspergillus were A. niger and A. fumigates, Alternaria alternata and Pencillium citrinum. Among these the frequency of Alternaria alternata was highest which has the capacity to produce mycotoxin which can contaminate and cause spoilage. The grain losses found in quantity and quality; can be in the form of depletion in seed viability, hardness, color, size and shape, grain weight and various biochemical parameters viz., protein, carbohydrate and vitamins under post harvest storages.
\end{abstract}

Key words: wheat, post-harvest, storage, sub-epidermal fungi and spoilage.

\section{Correspondence Author:}

E-mail: shijumathew_biotech@yahoo.com; Contact no.: (+251) 920126043

\section{Introduction}

Grain production in any country varies from year to year and hence the grains should be stored strategically from years of overproduction for use in year of under production. Grain quality after harvest is influenced by a wide variety of biotic and abiotic factors and has been studied as a stored grain ecosystem. Spoilage of stored grain by fungi is determined by a range of factors which can be classified into four main groups including (a) intrinsic nutritional factors, (b) extrinsic factors (c) processing factors and (d) implicit microbial factors. The factors produce fungal colonization within the stored grains (Wallace and Sinha, 1981; Sinha, 1995). In 1970s, it was considered for the first time that the stored grain as a manmade ecosystem which needed to be examined in a more holistic and ecological manner to enable a proper understanding of the processes occurring and to improve post-harvest management of stored food commodities of all types. The post harvest losses at the farm level have been estimated to be $3.28 \mathrm{~kg} / \mathrm{q}$ in wheat. The post harvest loss of wheat grain has been found to be highest during storage (Magan et al., 2003). Stored grains can have losses in both quantity and quality. Losses occur when the grain is attacked by microorganisms and other organisms including insects, mites, rodents and birds (Neetirajan et al., 2007).

The wheat grains come in association with the fungi from the time of grain maturity and also at the time of storage. Some of these fungi are in intimate association and are present as dormant mycelium under the pericarp or dormant spores on the surface of 
the kernel. However, there are a number of fungi which are only superficially associated with stored grains. The mycelium was usually septate, thin and branching repeatedly to form a network on the subepidermal surface of stored wheat grains. Sometimes, due to more frequent formation of transverse walls, beaded cells were seen. The sub-epidermal mycelium was observed even in apparently, healthy, undamaged grains examined superficially with hand lens. The association of fungi with cereal grains starts from the field itself. Shortly after the grain reaches to maximum size, the lemma and palea protecting it are pushed apart exposing the grain to infection by fungi (Machacek and Greaney, 1938) and their extensive studies has been carried out in the laboratory on these aspects (Sankaran et al., 1975; Sankaran, 1976; Sankaran et al., 1976). An extensive microflora has been found to be associated with stored wheat grains (Duggeli, 1904; Kent- Jones and Amos, 1930; James et al., 1946; Christensen, 1956; Poisson and Guilbot, 1956; Inagaski and Ikeda, 1959; Field and King, 1962; Brook and White, 1966; Graves et al., 1967; Pelhate, 1968; Hesseltine, 1968; Wallace, 1973). Earlier in the laboratory a number of cereals have been screened with respect to microflora associated in storage grains (Basu, 1974; Mehrothra, 1974; Palni, 1975; Jayas, 1995). Fungal activity can cause undesirable effects in grains including discolouration, contribute to heating and losses in nutritional value, produce off-odours, losses in germinability, deterioration in baking and milling quality, and can result in contamination by mycotoxins (Hocking, 2003; Magan et al., 2003).

\section{Materials and Methods}

The investigation was done at Allahabad Agricultural Institute-Demmed University, Allahabad in India. . The work was an attempt to correlate the sub-epidermal fungal infestation and quality of wheat grain under storage. The wheat samples were collected separately in 3 replicates for each of the wheat (Triticium aestivum L.) varieties viz., U.P. 262 and H.D. 1982 from F.C.I. godown, Naini, Allahabad district, whole sale dealers from Naini and Muttiganj markets of Allahabad and from the local farmers. The samples were brought to the laboratory under aseptic condition where they were screened (before washing and after washing with water) for their associated sub-epidermal fungal flora. Out of these, some samples were heavily infested with fungi, some were slightly infested and some were not at all infested. Twenty samples of wheat grains belonging to two different varieties were screened for the presence of sub-epidermal mycelium. Five different sample collection sites were selected and 12 month stored (moisture content 8-16\%) samples were screened within a week of their collection. One hundered grains from each samples were taken randomly, they were examined for the presence of sub -epidermal mycelium within the grain by the method of Hyde and Galleymore (1951) as described below:

1. The grain without cracks and holes on their epidermis were soaked in water for a short period and then the epidermis was peeled off with forceps.

2. The stored grains were also examined superficially with a hand lens $(10 \mathrm{X})$.

3. The peeled epidermis contains sub-epidermal mycelium.

4. The epidermis was then placed in aniline blue ( $0.2 \%$ in $66 \%$ lactic acid) and warmed for $5-10$ minutes which stained the mycelium alone and the epidermal cells were left unstained.

The sub-epidermal fungi was brought into culture by first surface disinfecting the soaked grains by immersion for two minutes in $0.2 \%$ sodium hypochlorite and washing in two changes of sterile water. Then the peeling of the epidermis were taken out and transferred to five different culture medium viz., Czapek's solution agar, Czapek's osmophilic solution agar, Malt extract agar, Wheat extract agar and oat meal agar with the following composition:

1. Czapek's solution agar media, Oat meal Agar Media and Malt extract agar: The composition of these media has been mentioned above.

2. Czapek's osmophilic solution agar: Same as Czapek's solution agar media except for sucrose which is $20 \%$ instead of $3 \%$.

3. Wheat extract agar: Wheat extract 20g; Agar, 30g; Yeast extract, 0.5g; Distilled water, $1000 \mathrm{ml}$.

The culture was incubated at $25 \pm 2{ }^{\circ} \mathrm{C}$ for 7 days.

Each set of experiment had a control to differentiate the laboratory contaminants from the microflora actually associated with the sample. The fungal colonies were isolated and identified with the help of authentic literature. The frequency of occurrence of different fungi isolated from wheat samples was calculated by the following formula; 
Total number of plates in which

Percentage frequency $=\frac{\text { a particular fungus appeared }}{\text { Total number of plates examined }} \times 100$

The various media used for the identification of subepidermal fungi with different composition of Czepek's solution agar $\left\{\mathrm{NaNO}_{3}(3.0 \mathrm{~g}) ; \mathrm{K}_{2} \mathrm{PO}_{4}(1.0 \mathrm{~g})\right.$; $\mathrm{KCL}(0.5 \mathrm{~g}) ; \mathrm{MgSO}_{4} .7 \mathrm{H}_{2} \mathrm{O}(0.5 \mathrm{~g}) ; \mathrm{FeSO}_{4} .7 \mathrm{H}_{2} \mathrm{O}(0.01 \mathrm{~g})$; Sucrose (30.0 g); Agar (20.0 g); Distilled water (1000.0 $\left.\left.\mathrm{ml}) ;{ }_{\mathrm{p}} \mathrm{H} 6.5\right)\right\}$, Czepek's yeast agar $\left\{\mathrm{K}_{2} \mathrm{HPO}_{4}(1.0 \mathrm{gm})\right.$; Czepek's concentrate (10.0 gm); Yeast extract (5.0 gm); Sucrose (30.0 gm); Agar (20.0 gm); Distilled water $(1000.0 \mathrm{ml}) ; \mathrm{pH}$ 6.5\}, malt extract agar \{Malt - Extract (20.0 g); Peptone (1.0 g); Dextrose (20.0 g); Agar (20.0 g); Distilled water $(1000.0 \mathrm{ml}) \mathrm{pH} 6.5\}$, Oat meal agar \{Oat meal (20.0 g); Yeast extract (0.5 g); Agar (20.0 g); Distilled water (1000.0 ml); $\mathrm{pH}$ 6.5\}, Potato-dextrose agar \{Potato Dextrose (20.0 g); Agar (20.0 g); Distilled water $(1000.0 \mathrm{ml}) ;{ }_{\mathrm{p}} \mathrm{H}$ 6.5\}, Peptone agar \{Peptone (10.0 g); Dextrose (20.0 g); Agar (20.0 g); Distilled water $(1000.0 \mathrm{ml}) ; \mathrm{pH} 6.5\}$ and Synthetic mucor agar \{ Dextrose (20.0 g); Asparagine (2.0 g); $\mathrm{KH}_{2} \mathrm{PO}_{4}(0.5 \mathrm{~g})$; $\mathrm{MgSO}_{4} .7 \mathrm{H}_{2} \mathrm{O}(0.25 \mathrm{~g})$; Thiamine chloride $(0.5 \mathrm{~g})$; Distilled water $(1000.0 \mathrm{ml}) ; \mathrm{pH}$ 6.5\}. These media were sterilized at $121^{\circ} \mathrm{C}$ and $15 \mathrm{lbs}$ p.s.i. for 20 minutes.

\section{Results and Discussion}

The result of sub-epidermal fungi in the stored wheat grain varieties U.P. 232 and H.D.1982 collected from different sites of Allahabad are given in Figure 1. Subepidermal mycelium was seen in all samples screened. These mycelia were usually septate, thin and branching repeatedly to form a network. Sometimes, due to more frequent formation of transverse walls, beaded cells were seen. Four species of fungi as shown in Table 1 were isolated from sub-epidermal region of wheat grains and the microscopic view is shown in Figure 2. The most common storage fungi observed in the stored wheat grain samples was Alternaria alternata (14.6\%). Species of Aspergillus were also encountered with $A$. fumigatus (10.5\%), and $A$. niger ( $8.3 \%$ ) followed by Penicillium citrinum (3.8\%). The sub-epidermal mycelium was observed even in apparently, healthy, undamaged grains examined superficially with hand lens prior to peeling. Sporophores were sometimes seen emerging from the groove region or from cracks and holes on the smooth surface of the stored wheat grain.

The entry of the fungus in stored grains could be through the epidermis as the sub-epidermal mycelium was observed even in apparently healthy grains examined superficially with a hand lens and prior to peeling. However, sporophores were sometimes seen emerging in the groove region or from the cracks and holes in the smooth surface. Simmonds (1968) observed that infection takes place through the cracks in the epidermis or the opening over the embryo since abundant fungal fruiting was evident where cracks had occurred. Welling (1968) found that Aspergillus species infected seeds independent of the amount of injury. The mature stored wheat grains were found to have more injury. Hyde and Galleymore (1951) observed that mature grains contain more internal mycelia. Flannigan (1974) also found Alternaria alternata in $78.5 \%$ of the wheat grains established fungi with Alternaria alternata was among the ones which appeared later.

Reports from various countries show that this species is found to be the most common post harvest fungi. Saponaro and Madaluni (1960) reported the presence of Aspergillus in stored wheat grains in Italy, Wallace and Sinha (1962) in Canada, Kurata et al. (1968), Tsunado (1970) and Tsuruta (1970) in Japan. However, James and Smith, 1948 from Canada reported $A$. niger stood second with respect to frequency of occurrence of fungi in stored wheat grains. Conversely Aspergillus and Penicillium are more often considered as 'storage fungi'. They are known to form mycotoxins in stored grains and are usually not regarded as fungi that can produce mycotoxins before harvest (Frisvad, 1995; Wicklow, 1995; Hockings, 2003)

\section{Acknowledgements}

I gratefully acknowledge the cooperation, uninterrupted guidance, impeccable and valuable suggestions rendered to me by Prof. (Dr.) George Thomas during my research work.
Table 1: Frequency of fungi isolated from sub -epidermal region of stored wheat

\begin{tabular}{|c|c|c|}
\hline S. No. & Organisms & Frequency of occurrence (\%) \\
\hline 1 & Alternaria alternata & 14.6 \\
\hline 2 & Aspergillus fumigatus & 10.5 \\
\hline 3 & Aspergillus niger & 8.3 \\
\hline 4 & Penicillium citrinum & 3.8 \\
\hline
\end{tabular}




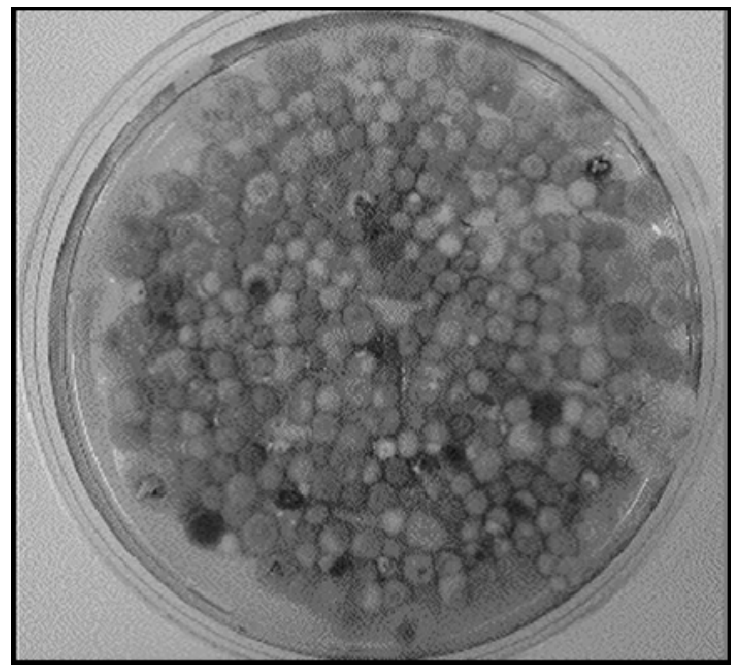

Figure 1: The colonies developed on the Czapek's solution agar of the stored grain fungi

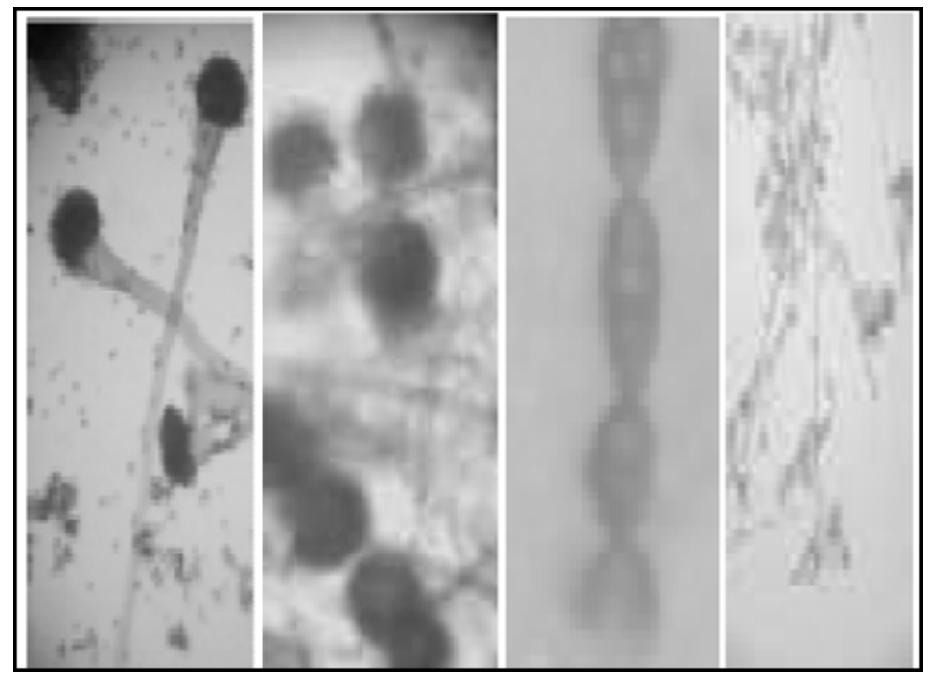

Figure 2: Schematic showing isolated fungal colonies under microscopic view i) Aspergillus fumigatus ii) Aspergillus niger iii) Alternaria alternate iv) Penicillium citrinum

Proceedings of the Australian Postharvest Technical Conference, Canberra. CSIRO Stored Grain Research Laboratory, Canberra. 2003; pp. 55-58.

Hyde M, Olly B, Galleymore HB: The subepidermal fungi of cereal grains II. The nature identify and origin of the mycelium in wheat. Ann. Application Biol. 1951, 8: 248-356.

Inagaski N, Ikeda M: Studies on the fungi isolated from foods II. Identification of Penicillia and Aspergilli from flour. Bull. Nat. Hygenic Lab. Tokyo. 1959, 77: 347-366.

James N, Wilson, J, Stark E: The microflora of stored wheat. Can. J. Res. 1946, 24: 224-233.

Jayas DS: Stored-grain ecosystems. New York: Dekker. 1995, pp. 757.

Kent-Jones DW, Amos AJ: Preliminary studies in bacteriology of wheat and flour. Analyst. 1930, 55: 248-268.

Machacek JE, Greaney FJ: The block point of kernel smudge disease of cereals. Can. J. Res. 1938, 16: 84113.

Magan N, Hope R, Cairns V, Aldred D: Post-harvest fungal ecology: impact of fungal growth and mycotoxin accumulation in stored grain. European $J$. Plant Pathol. 2003, 109: 723-730.

Mehrothra DK: Studies on some microrganisms associated with rice in storage. Paper presentation Abstract at University of Lucknow. 1974. 66.

Hocking AD: Stored grain in Australia 2003.
Neethirajan S, Karunakaran S, Jayas DS, White NDG: 
Detection techniques for stored-product insects in grain. Int. Fd. Control. 2007, 18: 157-162.

Palni IK: Studies on the microflora associated with wheat grains and various milling fraction. Paper presentation. Abstract, University of Lucknow. 1975.

Pelhate J: Inventaire de la mycoflora des bles de conservation (Inventory of mycoflora of stored wheat) Bull. Soc. Mycol. France 1968, 84: 127-143.

Poisson J, Guilbot MA: Mycoflora des Farines Franscaises. Menuerie, France 1956, pp 42-52.

Sankaran R: Mould Problems in the Storage of Food Grains. Symposium 'Stratergies on Storage, Handling and Processing of Food Grains in the Present Context'. Bangalore Chapter of Association of Food Scientists and Technologists, India 1976.

Sankaran R, Sehgal DD, Parihar DB, Nath H: Cereal grain fungi and grain quality. Def. Sci. 1976, 26: 161.

Sankaran R, Mattada RR, Thangamani: Mycoflora and changes of wheat seed quality during storage. Itzd. Fd. Packer. 1975, 29: 1.

Tsunoda H: Microorganisms which deteriorates stored cereals and grains. In: Toxic microorganisms ( $M$. Herzberg, ed.). Published by UJNR Joint Panels on toxic microorganisms and the U.S. Department of Interior Washington D.C. 1970.
Tsuruta O:. Microorganisms in stored grains. Training manual on storage and preservation of wheat grain 1970, pp. 307.

Tuite JF, Christensen CM: Grain storage studies 24: Moisture content of wheat seed in relation to invasion of seed by species of the Aspergillus glaucus group and the effect of invasion upon germination of the seed. J. Phytopathol. 1957, 47: 323-327.

U.S. Department of Agriculture: Annual World Production Summary, Grains, http://www.usda.gov/ Agriculture crop production. 2003.

Wallace HAH: Fungi and other organisms associated with stored grains in grain storage part of a system (R.N. Sinha and W.E. Muir, eds.). AVI publishing Co., Connecticut Sec. II Capt. 1973, 4 : 71-78.

Wallace HAH Sinha RN: Causal factors operative in distributional patterns and abundance of fungi: a multivariate study. In: The Fungal Community- Its Organisation and Role in Ecosystems (D.T. Wicklow and G.C. Carroll, eds.). Marcell Dekker Inc., New York. 1981, pp. 233-247.

Wicklow DT: The mycology of stored grain: an ecological perspective. In: Stored grain ecosystems (D. S. Jayas, N. D. G. White and W. E. Muir, eds.). New York, Marcel Dekker. 1995, pp. 197-249. 